\title{
2
}

\section{A CRISE ESTRUTURAL DO CAPITALISMO GLOBAL - O CAPITAL DIANTE DE SEUS LIMITES NO SÉCULO XXI*}

Giovanni Alves

Após dez anos da crise de 2008, o capitalismo global encontra-se novamente diante de uma profunda recessão global por conta da pandemia do novo. Mas a culpa do novo desastre econômico do capitalismo global não foi da pandemia. É parte natural do ciclo das economias capitalistas ter recessões. Entretanto, o problema não é ter recessão, mas sim, a dimensão que a desaceleração e queda que deve promover o acúmulo de contradições sociais e políticas num patamar superior desde a profunda recessão de 2008. Em 2008 o que salvou as economias capitalistas desenvolvidas diante do crash financeiro foram os Bancos Centrais que injetaram trilhões de dólares para salvar o sistema bancário ${ }^{1}$; e depois, foi aplicada uma política de afrouxamento monetário visando a recuperação das economias capitalistas (a estratégia do quantitative easing) ${ }^{2}$.

Decorridos dez anos da crise de 2008, percebe-se que o maior problema das economias capitalistas mais desenvolvidas é o alto endivi-

${ }^{*}$ DOI - - 10.29388/978-65-86678-37-6-0=f.49-66

${ }^{1}$ Em 2008, a quebra do Lehman Brothers tornou-se marco da crise que levou EUA e Europa a injetarem trilhões no mercado para evitar derrocada mundial, como a de 1929. Leia-se a reportagem "Após crise global estourar em 2008, bancos receberam socorros bilionários", O Globo, 05/08/2014. Disponível em: <https://acervo.oglobo.globo.com/em-destaque/apos-crise-globalestourar-em-2008-bancos-receberam-socorros-bilionarios-13495994 >. Acesso em: 06 nov. 2019.

${ }^{2}$ Quantitative easing (QE), conhecido também como flexibilização quantitativa, afrouxamento quantitativo ou política de harmonização financeira quantitativa é uma ferramenta de afrouxamento monetário que visa a criação de quantidades significantes de dinheiro novo eletronicamente, por um banco, mas autorizado pelo Banco Central, mediante o cumprimento das normas de percentuais pré estabelecidos. É um jargão para uma ação de política monetária do Banco Central. Os bancos centrais utilizam-se desta estratégia há muito tempo e mantém a sua prática como forma de reanimar a economia sem precisar confeccionar o dinheiro físico, mas só a partir das recessões de início dos anos 2000, no Japão, e da Crise do subprime, nos EUA, que esta medida se tornou expressiva. 
damento do setor público e do setor privado. ${ }^{3}$ Apesar da estratégia do quantitative easing, as economias centrais não conseguiram ter crescimento sustentável e diante das ameaças de desaceleração e inclusive, recessão, cresceu o temor de novo crash financeiro num cenário "explosivo": os Bancos Centrais não têm mais ferramentas monetárias para realizar injeções de dinheiro na economia tal como fizeram em 2008 (para além do quantitative easing, os bancos centrais têm utilizado as políticas de taxas de juros negativas ou NIRP, sigla em inglês - "Negative Interest Rate Policy") para fazer o dinheiro circular e deste modo, reanimar as economias endividadas. ${ }^{4}$

Mas, como temos salientado, a crise do capitalismo global desde 2008, pelo menos, diz respeito a seus fundamentos materiais: a crise estrutural de lucratividade por conta da pressão histórica da composição orgânica do capital. Na medida em que não existem perspectivas de lucratividade, reduz-se o investimento produtivo - o que faz o PIB crescer - e a massa de capital-dinheiro desloca-se para a esfera da especulação financeira.

Apesar do significativo aumento da Taxa de Exploração e o novo salto tecnológico da Quarta Revolução Industrial, a Taxa de Lucro não se recuperou de forma sustentável capaz de propiciar o desenvolvimento das economias capitalistas. Na medida em que a financeirização da riqueza capitalista não opera como movimento contratendencial à queda da taxa de lucro, mas apenas desloca as contradições do sistema, presenciamos provavelmente no começo da década de 2020, o esgotamento desta estratégia de deslocar as contradições do capital.

Desde 2018, há pouco mais de dez anos do big crash, as economias dos países capitalistas centrais se desaceleram, indicando a inversão do pequeno ciclo de crescimento que começou em 2017. De 2010-2014 te-

\footnotetext{
${ }^{3}$ Verificamos hoje no capitalismo global um nível de endividamento jamais visto desde a Segunda Guerra Mundial que ameaça inocular o veneno da próxima crise. Eis a manchete do El País: "Bomba da dívida mundial ameaça explodir". Disponível em: < https://brasil.elpais.com/brasil/ 2018/06/08/economia/1528478931 493457.html>. Acesso em: 06 nov. 2019.

4“Negative Interest Rate Policy (NIRP) Definition”. Disponível em: $<$ https://www.investopedia.com $/$ terms $/ \mathrm{n} /$ negative-interest-rate-policy-nirp.asp $>$. Ou ainda, para maiores esclarecimentos sobre tal estratégia da economia capitalista: <https://www.nexojornal.com.br/expresso/ 2019/10/14/Por-que-h\%C3\%A1-pa\%C3\%ADses-com-juros-negativos $>$. Acesso em: 06 nov. 2019.
} 
mos um primeiro ciclo de crescimento das economias centrais. Entretanto, logo tiveram uma desaceleração e queda, sem se configurar como recessão, que durou até 2016, voltando a crescer em 2017, mas não se sus tentando, indicando uma desaceleração em meados de 2018, com perspectiva de recessão global. O que se verifica desde 2008, são períodos curtos e insustentáveis de crescimento, seguidos de desacelerações e quedas que ameaçam uma nova recessão.

Por exemplo, leia-se o Gráfico 1 que demonstra a instabilidade da produção industrial diante da crise do capitalismo global. A produção industrial é bom indicador das perspectivas de crescimento da economia. Neste Gráfico, vemos que os EUA têm uma recuperação da produção industrial no começo de 2016, crescimento que prossegue até meados de 2018. Dentre as economias desenvolvidas, os EUA apresentam a melhor performance da produção industrial neste ciclo de crescimento pós-crise de 2008 (inclusive superior à China, que no começo de 2015 tem uma queda significativa, voltando-se a recuperar no começo de 2016, tal como a economia norte-americana. Entretanto, a produção industrial da China recupera-se de forma errática, começando a cair novamente no começo de 2018. A produção industrial da Alemanha mantém-se crescendo, oscilando pequenos ciclos de altas e baixas, desde o começo de 2015 até o começo de 2018, quando verificamos uma queda abrupta, seguindo a queda da produção industrial da China. De certo modo, no começo de 2018, a produção industrial cai em todos os países capitalistas desenvolvidos, principalmente na China, com impactos no crescimento do PIB chinês que caiu de forma significativa ${ }^{5}$.

\footnotetext{
5 "Economia da China cresce 6,6\% em 2018; taxa é a menor desde 1990", Disponível em: $<$ https://g1.globo.com/economia/noticia/2019/01/21/economia-da-china-cresce-66-em2018.ghtml>. Acesso em: 06 nov. 2019.
} 
Gráfico 1 - Produção Industrial

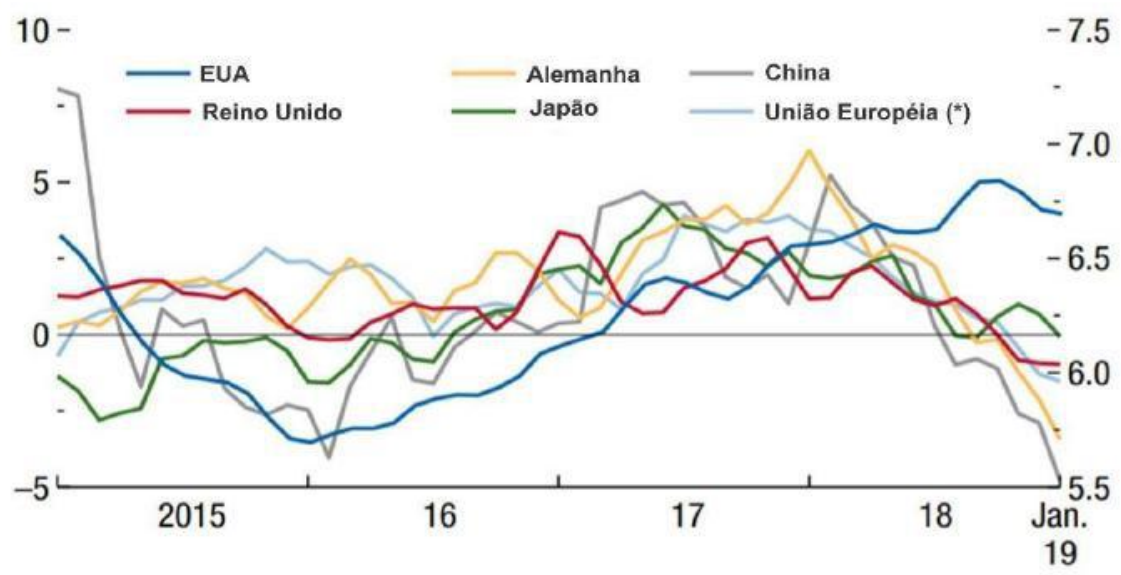

(*) França, Itália, Holanda e Espanha

Fonte: FMI, WORLD ECONOMIC OUTLOOK, Growth Slowdown, Precarious Recovery, 2019.

Façamos um alongamento da perspectiva de desenvolvimento do capitalismo mundial, pelo menos desde 1979. Os dados são do Fundo Monetário Internacional (FMI). Verificamos que, numa perspectiva de longa duração - pelo menos quarenta anos - de desenvolvimento do capitalismo global, o mundo tem oscilado altas e baixas taxas de crescimento e queda do PIB. A linha azul demonstra uma leve inclinação para baixo com uma queda abrupta em 2008 - o ano do crash financeiro global. A linha vermelha, que indica a evolução do PIB das economias desenvolvidas, o núcleo orgânico do capitalismo global, apresenta-se mais rebaixada ainda, descolando-se (para baixo) da linha azul, que indica a evolução do PIB mundial, no ano de 2000. Isso pode ser explicado pelo ciclo exuberante de crescimento da China, que deve ter elevado o crescimento do PIB mundial.

Verificamos isso no caso da evolução das economias emergentes e em desenvolvimento, que a partir de 2000 , tem um salto de crescimento do PIB, sendo a China responsável por isso até o crash de 2008, quando todas as economias do mundo caem e a partir de 2010, recuperam-se num patamar rebaixado. Mas o que interessa demonstrar neste Gráfico 2 
é a operação de tendência de queda da taxa de lucratividade pelo menos nos trinta anos de capitalismo global, operando com vigor - nos países centrais do capitalismo global - e de forma "contida" na China onde a lei do valor opera sob restrições. Mesmo assim, devido os vínculos orgânicos da China com o mercado mundial, a economia chinesa não deixa de ser afetada pelo movimento de crise do capitalismo global.

\section{Gráfico 2 - Crescimento do PIB (1970-2010)}

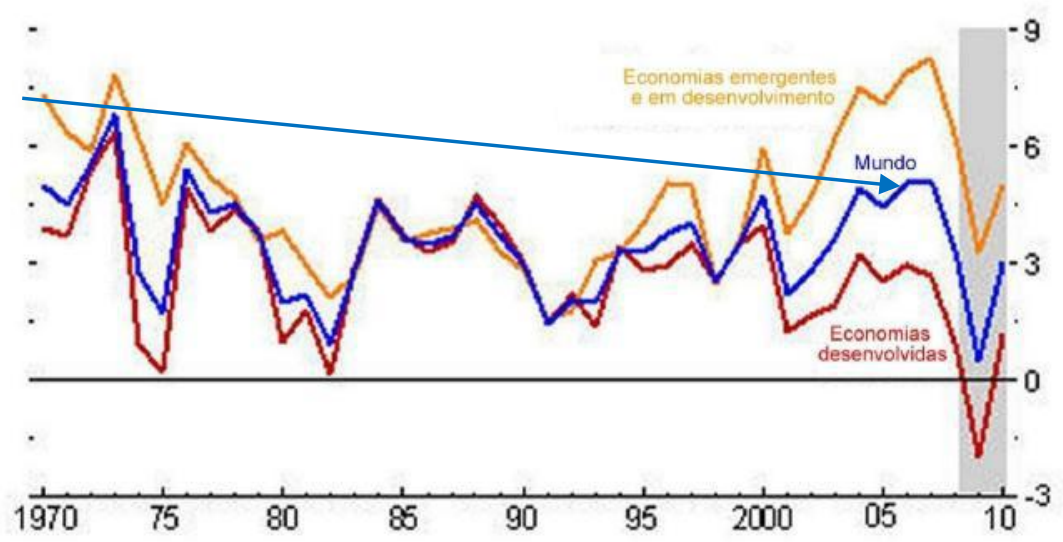

Fonte: FMI, Global Economic Slump Challenges Policies, 2009.

O Gráfico 3 apresenta a evolução da produção industrial, volume do comércio mundial e a tendência das ordens de compra da Manufatura global no que diz respeito à economia global. Nesse caso, incluem todos as economias do mundo. Verificamos a evolução descrita no Gráfico 1. No que diz respeito à produção industrial verificamos com clareza, um decrescimento até começo de 2016 a partir do qual a produção industrial volta a crescer e começa a cair novamente no começo de 2018. O volume do comércio mundial acompanha a produção industrial, alcançando altos níveis e tendo uma queda abrupta em meados de 2018 por conta da guerra comercial entre a China x EUA.

$\mathrm{O}$ indicador de tendência das compras de manufatura acompanha a produção industrial e volume do comércio mundial, indicando um rebaixamento em meados de 2017 e uma queda abrupta no começo de 2018. Todos os indicadores indicam uma desaceleração abrupta da eco- 
nomia global por conta de elementos contingenciais (guerra comercial China x EUA, Brexit, etc.) e elementos de fundo com respeito a indicadores de endividamento global com riscos sistêmicos e ainda, elementos estruturais, que temos salientado como sendo a taxa de lucratividade rebaixada e com dificuldades de aumentar por conta da pressão da composição orgânica do capital.

Gráfico 3 - Produção Industrial, Comércio Mundial e Tendência da Manufatura - Economia Global -

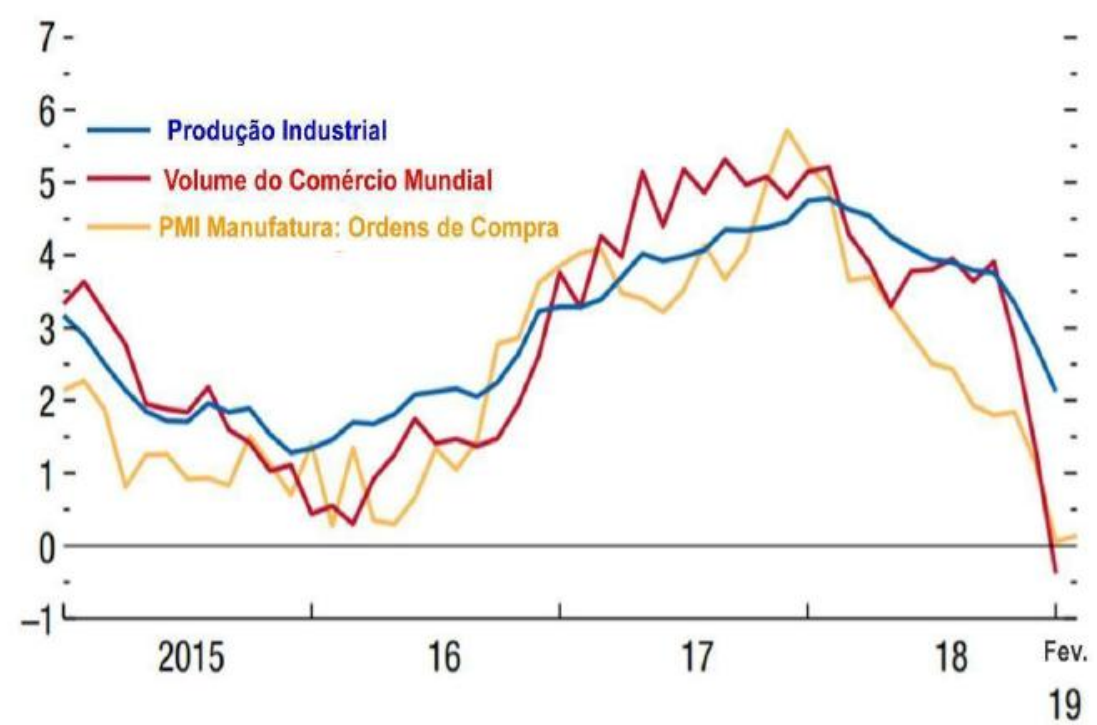

Fonte: FMI, WORLD ECONOMIC OUTLOOK, Growth Slowdown, Precarious Recovery, 2019.

Vejamos a taxa de lucro dos EUA, a economia capitalista dominante do núcleo do capitalismo global e que observamos seus ciclos de queda, recuperação e crescimento no que diz respeito a produção industrial no Gráfico 1. Na medida em que cresce a economia dos EUA exerce um efeito no Japão e União Europeia e inclusive América do Sul. As dificuldades na lucratividade nos EUA sinalizam problemas também em outros países do mercado mundial. O Gráfico 4 apresenta a evolução da lucratividade nos EUA desde o pós-guerra, demonstrando uma evolução descendente que oscila altos e baixos com ligeira inflexão para cima a 
partir de 2000 - a ascensão do capitalismo global - e uma oscilação para baixo em 2015.

Gráfico 4 - Taxa de Lucratividade (EUA) (1946-2018)

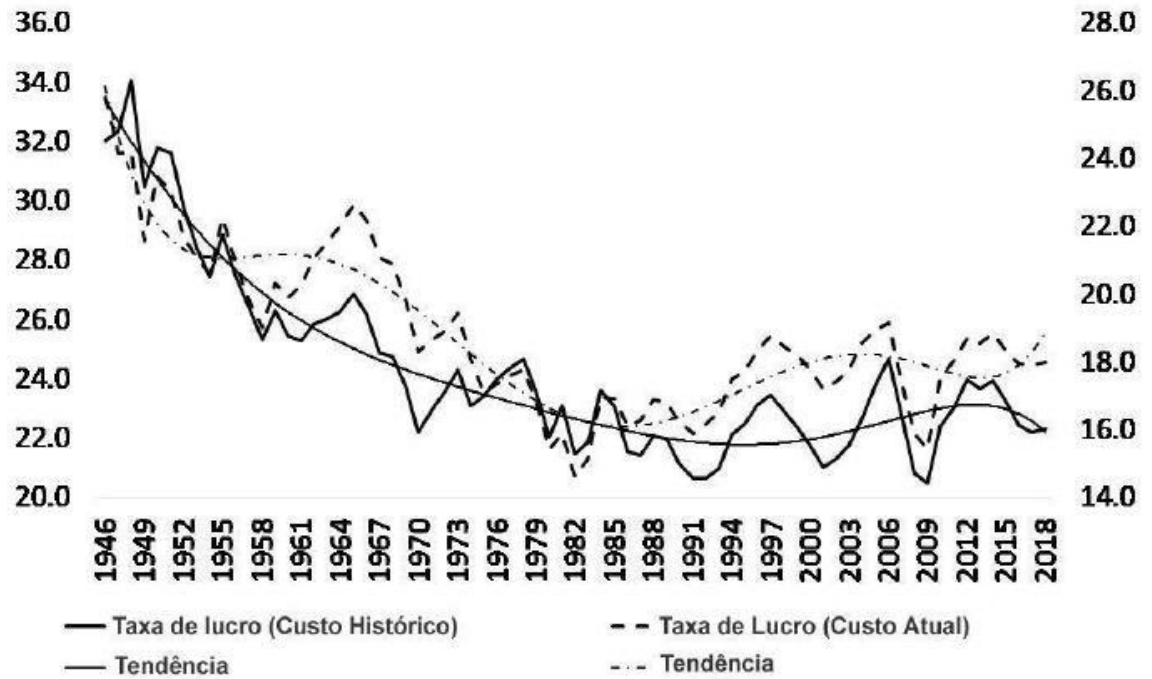

Fonte: Carchedi e Roberts (2018).

O Gráfico acima apresenta medidas da taxa de lucro nos EUA baseadas em custos históricos $(\mathrm{CH})$ e atuais $(\mathrm{CA})$. O que isso mostra é que a medida de custo atual atingiu seu ponto baixo no início dos anos 1980 e a medida de custo histórico não o fez até o início dos anos 1990. O que explica a diferença entre a medida da taxa de lucro pelo custo histórico e o custo atual é a inflação. Se a inflação estiver alta, como ocorreu entre os anos 1960 e o final dos anos 80, a divergência entre o custo histórico e o custo atual da medida da taxa de lucro será maior. Quando a inflação cai, a diferença nas mudanças entre as duas medidas de $\mathrm{CH}$ e CA diminui. De 1965 a 1982, a taxa de lucro dos EUA caiu 20\% pela medida do custo histórico: ou 35\% pela medida do custo atual. De 1982 a 1997, a taxa de lucro dos EUA aumentou apenas 9\% (pelo custo atual), ou aumentou 29\% (pelo custo atual). Mas durante todo o período do pós-guerra até 2018, houve uma queda secular na taxa de lucro dos EUA 
(pela medida do custo histórico de $30 \%$ e pela medida do custo também de $30 \%$ !).

Como observou Michael Roberts:

Os dados confirmam a explicação de Marx sobre as tendências da lucratividade. Segundo Marx, as mudanças na lucratividade dependem do movimento relativo de duas categorias do processo de acumulação do capital: (1) a composição orgânica do capital (c/v); e (2) a taxa de mais-valia (ou taxa de exploração) (m/v) - onde c é o capital constante; $\mathrm{v}$, o capital variável; e $\mathrm{m}$, a massa de maisvalia. Desde 1965, houve um aumento secular na composição orgânica do capital (medida pelo custo histórico) de $60 \%$, enquanto o principal elemento contratendencial à queda da taxa de lucro - a taxa de mais-valia - caiu mais de $9 \%$. Então a taxa de lucro caiu 30\%. Inversamente, no chamado periodo "neoliberal" de 1982 a 1997, a taxa de mais-valia aumentou $16 \%$, mais do que a composição orgânica do capital (11\%); então a taxa de lucro aumentou 9\%. Desde 1997, a taxa de lucro dos EUA caiu cerca de 5\%, porque a composição orgânica do capital aumentou quase $17 \%$, superando assim, o aumento da taxa de mais-valia (4\%). (ROBERTS, 2019, s/p. Grifo nosso). ${ }^{6}$

Desde 2011, a China reduziu o ritmo de seu crescimento, afetando o crescimento do PIB de países que dependem de exportações de commodities (como o caso do Brasil). Na verdade, embora tenha crescido $10,6 \%$ em 2010, reagindo à queda de 2008 e 2009 (9,7\% e 9,4\%), a partir de 2011, o PIB da China começa a decrescer (9,5 em 2011; 7,9 em 2012; 7,8 em 2013; e 7,3 em 2014), afetando por exemplo o Brasil e os países dependentes da venda de commodities (a queda lenta e persistentes do ritmo de crescimento da segunda maior economia do mercado mundial, continuaria nos anos seguintes: 6,9\% em 2015; 6,7\% em 2016; 6,8\% em 2017 e $6,6 \%$ em 2018. A guerra comercial com os EUA e a desaceleração do PIB de parceiros comerciais por conta da crise do capitalismo global, da qual faz parte a China, explicam o mais baixo índice de crescimento do PIB nos últimos 27 anos).

\footnotetext{
${ }^{6}$ ROBERTS, M. "US rate of profit measures for 2018”. Disponível em: < https://thenextrecession.wordpress.com/2019/11/04/us-rate-of-profit-measures-for-2018/>. Acesso em: 06 nov. 2019.
} 
Gráfico 5 - Crescimento da China - PIB 1990-2018

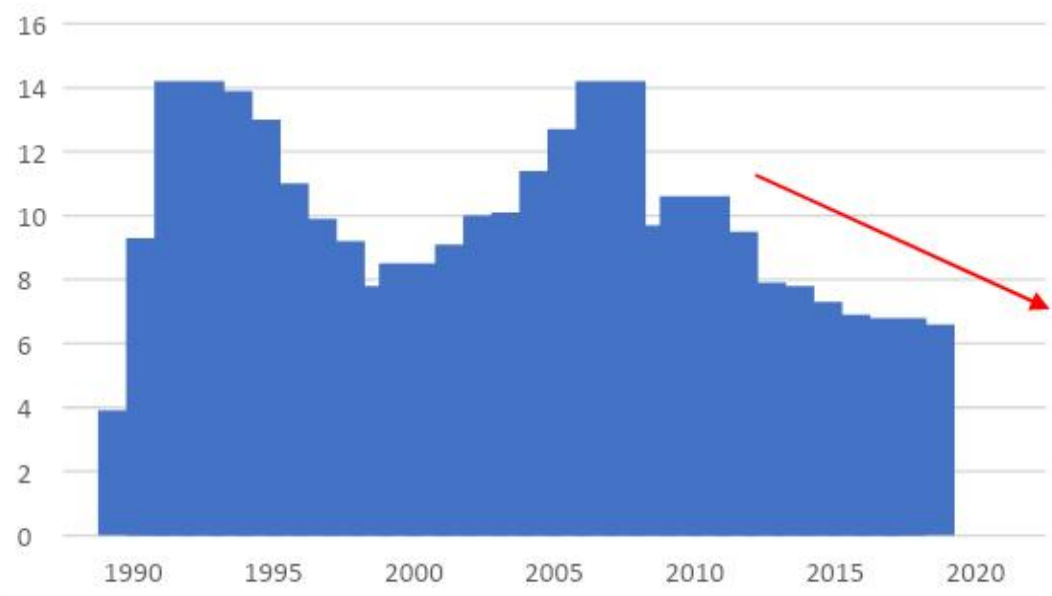

Fonte: FMI. Disponível em: <https://pt.countryeconomy.com>. Acesso em: 06 nov. 2019.

No decorrer da década de 2010, as economias dos países da América Latina acompanharam a desaceleração da economia global, tendo como principal referência a desaceleração da economia da China. A construção do modelo de desenvolvimento a partir da exportação de commodities $^{7}$, e não pela produção industrial com maior valor agregado, vulnerabilizou as experiências de desenvolvimento social na América latina

\footnotetext{
7“A palavra inglesa "commodity" significa simplesmente mercadoria. Mas no mercado o termo se refere a produto básico, em estado bruto ou com baixo grau de transformação. São mercadorias com pouco valor agregado e quase sem diferenciação - que podem, portanto, ser negociadas globalmente sob uma mesma categoria. Minério de ferro, madeira, carne e frango "in natura" e petróleo são algumas das mais comercializadas. O frango in natura produzido no Brasil e exportado para o mundo todo é uma commodity. Já produtos feitos a partir dele, como nuggets e salsichas, não. O que faz um nugget deixar de ser commodity é seu grau de processamento. Não é commodity por ser diferenciado. Esses produtos são divididos em agrícolas e minerais. Os agrícolas englobam culturas como soja, milho, algodão, açúcar. Os minerais vão desde o minério de ferro até o petróleo, passando pelo cobre e o ouro. As commodities representam $\underline{65 \%}$ do valor das exportações brasileiras, segundo levantamento de 2014 da Conferência das Nações Unidas sobre Comércio e Desenvolvimento (UNCTAD). As dez primeiras posições no ranking do MDIC (Ministério do Desenvolvimento, Indústria e Comércio Exterior) de produtos mais exportados são ocupadas por commodities. Com a exportação de commodities representando 6,8\% do PIB brasileiro (UNCTAD, 2014), a queda dos preços e a redução da demanda chinesa a partir de 2011 colaboraram para que os resultados na economia se deteriorassem". Apud "As commodities e seu impacto na economia do Brasil". Disponível em: < https://www.nexojornal.com.br/explicado/ 2016/03/31/As-commodities-e-seu-impacto-na-economia-do-Brasil>. Acesso em: 07 nov. 2019.
} 
(como, por exemplo, a Venezuela, Argentina e Brasil). O Gráfico abaixo nos mostra a queda dos preços de commodities que afetou as economias latino-americanas a partir de 2011 e que corresponde com a desaceleração do crescimento da economia chinesa.

Gráfico 6 - Índice de Preços de Commodities 2012/2013 média = 100

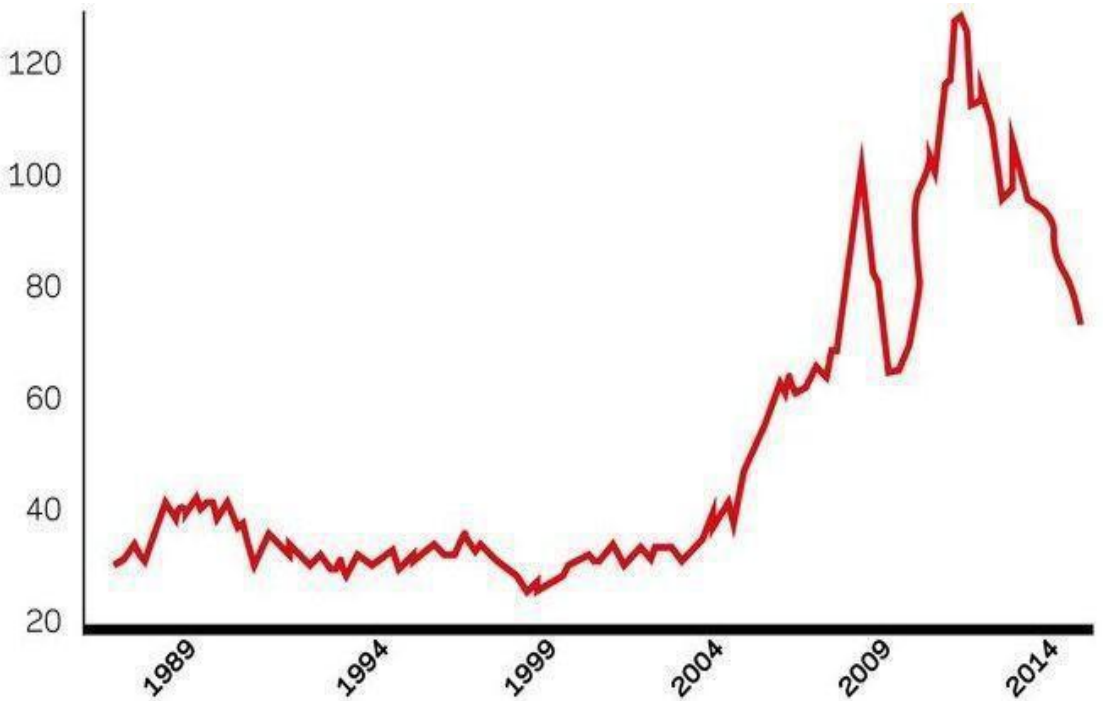

Fonte: Reserve Bank of Australia. Disponível em: <https://www.rba.gov.au/chart-pack/ commodity-prices.html>. Acesso em: 06 nov. 2019. .

O caso do Brasil é o exemplo trágico: enfrentou a maior recessão da história em 2015-2016, em parte provocada pelas medidas de austeridade neoliberal adotada pelo ministro Joaquim Levy (governo Dilma); e depois, de 2017-2018, com a política hiperliberal do ministro Henrique Meirelles (governo Temer) e a continuidade da crise política e social, a economia brasileira permaneceu estagnada, perdendo, nesse período, o momentum de crescimento das economias desenvolvidas.

Como vimos, diante da crise de lucratividade, o movimento do capital opera como principal contratendência, o aumento da Taxa de Exploração e/ou a desvalorização do capital constante. Como vimos, nos EUA, desde meados da década de 1960 verifica-se o aumento secular na Composição Orgânica do Capital (COC) que tem pressionado para baixo a Taxa de Lucratividade nos EUA. Entretanto, para operar o movimento 
contratendencial, o principal recurso tem sido o aumento da Taxa de Mais-Valia (ou Taxa de Exploração). Caso a COC cresça e a Taxa de Mais-Valia não acompanhe o crescimento, a Taxa de Lucro deve cair foi o que vimos acima. Nos EUA, o neoliberalismo da década de 1980 contribuiu para aumentar a Taxa de Mais-Valia, que cresceu mais do que a COC, elevando, deste modo, a Taxa de Lucro das empresas. Pelos dados de Michael Roberts, de 1982 a 1997, a Taxa de Mais-Valia aumentou 16\%, mais do que a Composição Orgânica do Capital (COC) (11\%), então a taxa de lucro aumentou 9\%. Entretanto, diz ele, para que a Taxa de Lucro continuasse aumentando, era necessário que a Taxa de Mais-Valia crescesse acima do aumento da COC, o que não ocorreu. Não é que a Taxa de Exploração não tenha aumentado, mas o aumento da COC foi maior. Portanto, a crise do capitalismo global se desenvolve num cenário histórico em que o capital precisa fazer a Taxa de Exploração aumentar mais do que o crescimento da COC - o que deve ser bastante improvável.

A questão que se coloca é saber em que medida a Quarta Revolução Industrial vai contribuir para o aumento da COC nos próximos anos (ou décadas), colocando a necessidade do capital aumentar a Taxa de Exploração num patamar superior ao aumento da COC. O desenvolvimento da gig economy (economia de bicos) e o novo patamar de precarização estrutural do trabalho visam realizar tal necessidade da acumulação de capital. Ao mesmo tempo, o capital pode efetuar um movimento de desvalorização do capital constante por meio da renovação tecnológica das empresas (o que vai exigir maior capacidade financeira delas).

A necessidade do aumento da Taxa de Exploração (ou da Taxa de Mais-Valia) é o que explica a precarização estrutural do trabalho no capitalismo global. A disseminação da superexploração do trabalho para além do capitalismo dependente é outro movimento do capital visando aumentar a Taxa de Exploração. Tanto a exploração, quanto a superexploração, articulam-se com o tecnocapitalismo e o novo imperialismo do século XXI, colocando novos elementos da transfiguração crítica do processo de trabalho e das cadeias de valor no século XXI. 


\section{A CRISE DE LONGA DURAÇÃO DO SISTEMA DO CAPITAL}

A crise do capitalismo global é uma crise de longa duração histórica marcada por altos e baixos da conjuntura da economia e da política. Salientamos que a crise estrutural do capital diz respeito à crise do modo de produção capitalista e crise do modo de controle sociometabólico estranhado (a relação-capital), que tem caracterizado secularmente as sociedades humanas de classe. Portanto, não se trata apenas de uma crise do modo de produção cujo declínio iniciou-se em meados da década de 1970 com a primeira grande recessão global do capitalismo do pósguerra.

O capitalismo global representa a forma histórica no interior da qual se desenvolve o declínio do capitalismo como modo de produção. Trata-se de um processo de longa duração histórica que deve percorrer o século XXI. Não se trata apenas do declínio do capitalismo como modo de produção, mas o colapso das formas da relação-capital como regulação sociometabólica. Aprofundou-se o estranhamento social na forma de fetiches (fetichismo da mercadoria, fetichismo do Estado, fetichismo da Técnica etc.) e assistimos o progressivo colapso ambiental no que diz respeito à relação homem x natureza e homem x homem. Portanto, não se trata apenas de crise do capitalismo, sim a crise do capital como forma histórica, colocando em risco, pela primeira vez na história da humanidade, a própria existência do homem como espécie no planeta Terra (nenhuma crise do modo de produção adquiriu tal radicalidade histórica).

A crise do capitalismo global contém em si como elemento de fundo estrutural o desenvolvimento de tendências indicadas por Marx na sua crítica da economia política. Identificamos a crise do capitalismo como tendo como um dos seus elementos compositivos, a crise estrutural de lucratividade (como salientamos acima).

Resgatamos uma interpretação ortodoxa da crise capitalista na perspectiva de Marx e Engels. Existem uma controvérsia entre marxistas sobre o significado da categoria da queda da taxa de lucro no desvendar da natureza da crise capitalista. Vários autores marxistas não apenas negam a lei do valor, mas negam a interpretação da crise pela lei de queda tendencial da taxa de lucro. Entretanto, nas últimas décadas, verificou-se 
um acúmulo de evidências históricas da ação da lei tendencial de queda da taxa de lucro. O debate marxista enriqueceu-se nas últimas décadas ao mesmo tempo que o capitalismo expõe sua incapacidade de crescer. Afirma-se o que autores neokeynesianos denominam de estagnação secular - no caso dos EUA. Tais evidências históricas representam na nossa perspectiva, a operação de longa duração da lei tendencial de queda da taxa de lucratividade.

Inclusive afirmamos que existe uma "crise estrutural" no sentido de que se fechou a possibilidade do capitalismo como modo de produção repetir ciclo de crescimento e bem-estar como ocorreu no século XXI. As dificuldades de valorização do capital que se expõem como crises financeiras são dificuldades estruturais. O capitalismo como modo de produção está "afetado de negação" - utilizando a linguagem dialética (nunca a lógica dialética foi tão indispensável para apreender o sistema social em sua etapa de crise estrutural). Como diria Marx, ocorre num patamar de maior densidade histórica, a suprassunção do capitalismo no interior do próprio capitalismo (suprassunção como negação, superação e conservação).

Temos utilizado o conceito de "duplo negativo do capital" para explicar a crise estrutural do capitalismo global. Ele diz respeito, por um lado, à crise estrutural da lucratividade; e, por outro lado, à desmedida do valor (o movimento de expansão do capital tende a suprassumir as bases de sua própria valorização). O duplo negativo do capital tem sido intensificado pelo tecnocapitalismo ou as mudanças tecnológicas em curso que aumentar a produtividade do trabalho.

As alterações tecnológicas na composição orgânica do capital são de fundamental importância para apreender os elementos de fundo que determinam o desenvolvimento do sistema de produção de mercadorias e acumulação de mais-valor. Portanto, o duplo negativo ou o duplo movimento que afeta de negatividade o movimento do capital e seu modo de produção, aparecem na nossa exposição como a dimensão da objetividade que, por si só, não é suficiente para vislumbramos a efetividade da crise do capital no sentido pleno da palavra.

A ação histórica da luta social e política das classes é elemento de necessidade, pois a história é feita pelos homens, embora sob determina- 
das condições. Mas a ação histórica ocorre dentro de limites materiais, pois não dependem só da vontade política dos agentes, embora se possa construir fantasias e ilusões, logo negadas pelo movimento objetivo da economia política.

Perguntemos: diante do movimento do "duplo negativo" como deve operar a luta de classes? Quais as questões políticas e sociais que devem se expressar como telos do movimento das massas do proletariado no século XXI?

O duplo negativo do capital opera com contradições candentes na medida em que se desenvolve o tecnocapitalismo. Temos salientado que o movimento de mudança tecnológica na produção tende a corroer as bases da própria valorização do capital. Mas além da intensificação das mudanças tecnológicas, inclusive como forma de desvalorização do capital constante, explicita-se, cada vez mais, no século XXI, a disputa política acirrada pelo fundo público (o espaço do Anti-valor), a partir das quais se constituem as reivindicações candentes da massa do proletariado por conta da crise social decorrente da expansão da "nova precariedade salarial" (a luta pelos direitos trabalhistas, sociais e previdenciários); da crise demográfica, tendo em vista o envelhecimento da população mundial e a necessidade de serviços de saúde e educação de novo tipo; e da crise ecológica na medida em que avança o colapso ambiental e a necessidade de acolhimento das vítimas do aquecimento global.

No decorrer do século XXI, deve-se ampliar a crise da democracia liberal, aprofundada como crise de legitimidade do poder político do capital. O capital deve acirrar o poder da ideologia e expandir a manipulação social e novos processos de subjetivação alienada visando retardar/bloquear a formação da consciência crítica das massas de proletários. Devem surgir formas de "Estado de exceção". Podemos dizer que o "Estado de exceção" é o Estado capitalista do século XXI cujo fundo público foi desativado como elemento de legitimidade política, apelando para dispositivos de repressão policial ou militar (necropolítica). Deve se aprofundar a crise de representatividade política das massas, dificultando o encaminhamento de saídas políticas para problemas estruturais no interior da "ordem democrática". Mas a crise do capital deve se deslocar para dentro do próprio Estado, na medida em que o Estado político é o 
Estado do capital no interior do qual devem ocorrer a luta de classes como luta de vida e morte (aprofundamento da crise social e conflitos políticos complexos nas várias "democracias capitalistas").

Os limites da financeirização como forma de deslocamento das contradições do capital se expõe na medida em que as crises financeiras se tornam ameaças para a sobrevivência do próprio sistema de poder do capital. Os movimentos de contenção do capital fictício devem aprofundar a crise do capitalismo senil, pois o sistema será obrigado a dar resposta às contradições na sua origem (o modo de produção de valor).

A massa de capital-dinheiro incapaz de autovalorizar-se, deve provocar o "colapso" da forma-valor, um "colapso" que se prolonga no tempo-espaço. $\mathrm{Na}$ verdade, a forma-valor se encontra "afetada de negação". Mas deve ser salientado que o valor é uma relação social de poder, o que significa que as contradições estruturais do sistema devem se resolver no plano histórico da luta de classes - mesmo que isso possa significar sua auto-extinção.

Talvez o impedimento do deslocamento das contradições na direção da financeirização possa reativar os movimentos contratendenciais clássicos à crise de lucratividade, embora eles manifestem os limites de sua eficácia histórico-social e político-moral (por exemplo, o aumento da Taxa de Exploração, levando ela a interverter-se em "superexploração"; e o aumento da velocidade de "obsolescência planejada" dos valores de uso, tal como indicou Mészáros no seu livro clássico "Para Além do Capital" (2003).

Enfim, o capital como valor, na sua etapa de crise estrutural, defronta-se com seus limites, tendo em vista que os limites fazem parte da sua própria natureza. O valor - na medida em que se "acoplou" ao capital - tornou-se uma forma de ser que desde sempre, colocou obstáculos para si, superando-os efetivamente. Entretanto, diante da sua crise estrutural, o capital como valor em processo, encontra-se não diante de barreiras - plenamente superáveis - mas sim, diante de limites que representam o próprio capital como causa sui (a causa de si próprio). 


\section{REFERÊNCIAS}

Canal G1. Economia da China cresce 6,6\% em 2018; taxa é a menor desde 1990. G1, 21 jan. 2019. Disponível em: <https://g1.globo.com/economia/noticia/2019/01/21/economia-da-china-cresce-66-em-2018.ghtml>. Acesso em: 06 nov. 2019.

CARCHEDI, G.; ROBERTS, M. World in Crisis: A Global Analysis of Marx's Law of Profitability. Chicago: Haymarket Books, 2018.

Countryeconomy. Disponível em: https:/ / pt.countryeconomy.com/ Acesso em 06 de nov. de 2019.

El País: "Bomba da dívida mundial ameaça explodir". Disponível em: <https://brasil.elpais.com/brasil/2018/06/08/economia/ 1528478931_493457.html>. Acesso em: 06 nov. 2019.

FMI. Global Economic Slump Challenges Policies. 2009. Growth Slowdown, Precarious Recovery. 2019.

HAYES, A. Negative Interest Rate Policy (NIRP) Definition. Investopedia, 26 mar. 2020. Disponível em: < https://www.investopedia.com/ terms/n/negative-interest-rate-policy-nirp.asp >. Acesso em: 06 nov. 2019.

MÉSZÁROS, István. Para além do capital: rumo a uma teoria da transição. Trad. de Paulo César Castanheira e Sérgio Lessa. São Paulo: Boitempo, 2003.

O Globo. Após crise global estourar em 2008 bancos receberam socorros bilionários. O Globo, 05 ago. 2014. Disponível em: <https://acervo.oglobo.globo.com/em-destaque/apos-crise-global-estourar-em-2008bancos-receberam-socorros-bilionarios-13495994>. Acesso em: 06 nov. 2019. 
Reserve Bank of Australia. Conferência das Nações Unidas sobre Comércio e Desenvolvimento UNCTAD, 2014. Disponível em: $<$ https://www.rba.gov.au/chart-pack/commodity-prices.html >. Acesso em: 06 de nov. 2019.

ROBERTS, M. US rate of profit measures for 2018. Michael Roberts Blog, 4 nov. 2019. Disponível em: <https://thenextrecession.wordpress.com/2019/11/04/us-rate-of-profit-measures-for-2018/>. Acesso em: 06 nov. 2019. 